\title{
Role of Oxidative Stress in the Colonic Complications of Murine Syngeneic Graft-versus-host Disease
}

\author{
Jacqueline Perez $^{1}$, J. Anthony Brandon ${ }^{2}$, Donald A. Cohen ${ }^{1,2,5}$, C. Darrell Jennings ${ }^{3,5}$, Alan. M. \\ Kaplan $^{1,2,5}$ and J. Scott Bryson*,1,2,4,5 \\ ${ }^{1}$ Graduate Center for Toxicology \\ ${ }^{2}$ Departments of Microbiology, Immunology and Molecular Genetics \\ ${ }^{3}$ Pathology and ${ }^{4}$ Internal Medicine, Division of Hematology and Blood \& Marrow Transplantation \\ ${ }^{5}$ Markey Cancer Center, University of Kentucky Medical Center, Lexington, KY, 40536
}

\begin{abstract}
Syngeneic graft-versus-host disease (SGVHD) develops in mice following lethal irradiation, reconstitution with syngeneic bone marrow (BM) and treatment with a short course of the immunosuppressive agent cyclosporine A (CsA). The development of SGVHD is a complex process resulting from the cooperative interaction of multiple effector cell populations and inflammatory mediators contributing to the pathogenesis of this inducible disease. Using gene expression analysis, flow cytometric analysis and immunohistochemistry, time course studies revealed increased reactive oxygen and nitrogen species in the tissues of CsA-treated animals compared to bone marrow transplantation (BMT) controls during the induction of SGVHD (d0-21 post-BMT). Studies were undertaken to determine the effect of CsA-induced oxidative stress on the induction of SGVHD. In vivo treatment with the superoxide dismutase mimetic, manganese (III) meso-tetrakis (4-benzoic acid) porphyrin (MnTBAP), during (d0-21 post BMT), or after CsA therapy ( $>\mathrm{d} 21$ post-BMT), caused a reduction in the development of clinical symptoms of SGVHD (weight loss, diarrhea). Interestingly, treatment with MnTBAP resulted in a significant reduction in the deposition of peroxynitrite in the colons of CsA-MnTBAP-treated versus control CsA-treated SGVHD animals. These studies suggest a role for oxidative stress in the development of murine SGVHD.
\end{abstract}

Keywords: Manganese (III) meso-tetrakis (4-benzoic acid) porphyrin, Nitrotyrosine, Reactive Nitrogen Species, Reactive Oxygen Species, Syngeneic graft-versus-host disease.

\section{INTRODUCTION}

Syngeneic graft-versus-host disease was described by Glazier et al. as a graft-versus-host disease (GVHD)-like syndrome that developed in rats following syngeneic bone marrow transplantation (BMT) and cyclosporine A (CsA) treatment [1]. SGVHD is induced by reconstituting lethally irradiated mice with syngeneic BM cells followed by a 21 day treatment with CsA. Both radiation and CsA are required for the development of SGVHD. Radiation allows for the elimination of regulatory cells that are capable of modulating the induction as well as the adoptive transfer of SGVHD [2, $3]$. It has been demonstrated that cell killing by ionizing radiation is mediated primarily through the induction of oxidative stress [4]. CsA is an immunosuppressive drug commonly used to prevent graft rejection following solid organ transplantation or to prevent GVHD following allogeneic BMT $[5,6]$. Administration of CsA to rats has been shown to cause overproduction of reactive oxygen species (ROS),

*Address correspondence to this author at the Department of Internal Medicine, Division of Hematology and Blood \& Marrow Transplantation, Markey Cancer Center, University of Kentucky, 800 Rose Street, Lexington, Kentucky 40536; Tel: 859-323-2889; Fax: 858-257-7715;

E-mail: jsbrys@.uky.edu as well as increased reactive nitrogen species (RNS), shown by elevated inducible nitric oxide synthase (iNOS) and nitrotyrosine levels [7-9].

In the mouse, clinical symptoms of SGVHD (weight loss, diarrhea) appear 2 to 3 weeks following cessation of CsA therapy with disease-associated inflammation occurring primarily in the colon and liver $[10,11] . \mathrm{CD}^{+} \mathrm{T}$ cells have been shown to be the predominant effector cell in the pathogenesis observed in murine SGVHD [12, 13]. Associated with a defined role for $\mathrm{CD} 4^{+} \mathrm{T}$ cells, previous studies have demonstrated significantly higher levels of $T_{H} 1$ and $T_{H} 17$ cytokines in target organs of SGVHD mice [14-17].

In addition to $\mathrm{CD}^{+} \mathrm{T}$ cells and inflammatory cytokines, RNS have also been shown to play a significant role in the development of SGVHD [18]. Nitric oxide (NO) is a ubiquitous molecule needed for normal physiologic functions and is generated from L-arginine through an oxidation reaction that is catalyzed by NO synthase (NOS). The inducible form of NOS (iNOS, NOS2) can be expressed in many cell types, and it also exhibits immunosuppressive properties that may play a role in the down-regulation of immune responses [19]. By itself NO is a weak free radical but in combination with other ROS, such as superoxide $\left(\mathrm{O}_{2}^{-}\right)$, it can result in the for- 
mation of peroxynitrite $\left(\mathrm{ONOO}^{-}\right)$, a toxic and reactive product capable of mediating cytotoxic processes [20, 21]. The contribution of NO to the development of murine SGVHD was previously determined by the treatment of mice with the iNOS inhibitor aminoguanidine (AG) during the post-CsA period. Inhibition of iNOS resulted in the abrogation of clinical symptoms, tissue pathology and inflammatory cytokine levels associated with the development of SGVHD [18]. Inhibition of iNOS also resulted in reduced pathophysiology associated with allogeneic GVHD [22, 23]. Conversely, NO has been shown to have a protective effect during the early stages of GVHD induction (days 0 up to 14 post-BMT) and inhibition of iNOS resulted in decreased survival [24, 25].

The role of oxidative stress in the pathophysiology of diseased states [9, 21] has led to the development of metalloporphyrin catalytic antioxidants as a possible therapeutic option. MnTBAP is a stable metalloporphyrin that can scavenge a broad spectrum of reactive oxygen and nitrogen species [26-30]. This compound can scavenge peroxynitrite [30], catalyze the dismutation of superoxide [29] and protect DNA from ROS-mediated damage. MnTBAP has been successfully used to prevent oxidant-induced injury responses by activated macrophages both in vitro and in vivo [28, 29]. As CsA therapy after syngeneic BMT increased NO production [18] and CsA toxicities are associated with the generation of oxidative stress, studies were undertaken to investigate the role of oxidative stress in the development of SGVHD. Mice treated with CsA had higher levels of reactive oxygen and reactive nitrogen species compared to control animals. Recipient mice were treated with the antioxidant MnTBAP during the induction SGVHD (d0-21 postBMT) or post-CsA therapy ( $>21$ day post-BMT) to further analyze the role of reactive oxygen/reactive nitrogen species in the development of SGVHD. BMT mice given MnTBAP either during or after CsA-therapy produced decreased levels of RNS and decreased clinical symptoms and induction of SGVHD. Collectively, these data suggest a role for oxidative stress in the intestinal pathogenesis of murine SGVHD.

\section{MATERIALS AND METHODS}

\section{Mice}

$\mathrm{C} 3 \mathrm{H} / \mathrm{HeN}$ mice were purchased from Harlan SpragueDawley (Indianapolis, IN) at 20-21 days of age and were used within 1 week of arrival. Mice were housed in sterile microisolator cages (Lab Products, Maywood, NJ) and fed autoclaved food and acidified water ad libitum. Animal protocols were reviewed and approved by the University of Kentucky Institutional Animal Use and Care Committee.

\section{Induction of SGVHD}

Bone marrow was isolated from the femurs and tibias of syngeneic age-matched mice. The donor BM suspensions were prepared in RPMI 1640 (Cellgro, Herndon, VA) supplemented with $100 \mathrm{U} / \mathrm{ml}$ penicillin and $100 \mu \mathrm{g} / \mathrm{ml}$ streptomycin. The resulting cell suspensions were depleted of Thy$1^{+}$cells using mAb to Thy-1.2 (HO-13-4) and Low Tox M rabbit complement (Cedarlane Laboratories, Westbury, NY), as previously described [31]. Recipient mice were lethally irradiated with $900 \mathrm{cGy}$ in a Mark I ${ }^{137} \mathrm{Cs}$ irradiator (J.L.
Shepherd and Associates, Glendale, CA). The animals were reconstituted i.v. with $5 \times 10^{6} \mathrm{~T}$ cell-depleted BM (ATBM) 4-6 h after conditioning. Beginning on the day of transplantation, the mice were given daily i.p. injections for 21 days with either CsA (15 mg/kg; purchased through the Division of Laboratory Animal Resources, University of Kentucky) in the diluent olive oil (Sigma-Aldrich, St. Louis, MO) or with diluent alone. Following cessation of CsA therapy, the animals were weighed three times per week and observed for clinical signs of SGVHD (weight loss, diarrhea). Animals that developed clinical symptoms for three consecutive weighings, developed weight loss or died due to disease were considered as positive for the induction of SGVHD.

\section{In Vivo Treatment with MnTBAP}

Treatment with MnTBAP was performed either during or post-CsA therapy. For MnTBAP therapy during the CsA period, treatment began two days prior to BMT and mice were treated i.p. with $10 \mathrm{mg} / \mathrm{kg}$ of MnTBAP (Axxora Life Sciences Inc., San Diego, CA.) ending at day 21 post-BMT. A twice a day dosing regimen was used based on the MnTBAP elimination half-time of 9.5 hours [32]. For postCsA treatment, twice daily MnTBAP therapy began at day 21 post-BMT and was given for 2-3 weeks. Treatment was stopped when the majority of the CsA group $(>80 \%)$ had developed SGVHD. Following cessation of CsA therapy, the animals were monitored for the development of clinical symptoms of SGVHD as described.

\section{Flow Cytometry Analysis of ROS by DCFH-DA}

At 21 days after BMT, control, CsA- and MnTBAPtreated mice were euthanized by $\mathrm{CO}_{2}$ inhalation and the spleens removed. Single cell suspensions were prepared from individual spleens and the red blood cells were lysed by treatment with $0.83 \%$ Tris-buffered $\mathrm{NH}_{4} \mathrm{Cl}$. The resulting cell population was counted using trypan blue exclusion and intracellular ROS were detected using the cellular marker 2',7'-dichloro-dihydrofluroscein diacetate (DCFH-DA) following the method of Saito et al. [33]. Briefly, isolated lymphoid cells $\left(2 \times 10^{6}\right.$ cells $\left./ \mathrm{ml}\right)$ were washed once and resuspended in phosphate-buffered saline (PBS). Cells were labeled by incubation for $30 \mathrm{~min}$ at $37^{\circ} \mathrm{C}$ with DCFH-DA at a final concentration of $5 \mu \mathrm{M}$. After incubation, cells were washed twice with PBS and fixed in 1\% paraformaldehyde. Flow cytometric analysis was performed on a BD Biosciences FACSCalibur flow cytometer (San Jose, CA).

\section{Histological Evaluation of SGVHD}

Tissue samples were taken from euthanized animals and immediately placed in $10 \%$ buffered formaldehyde. Fixed tissues were embedded in paraffin, cut into 4- to 6- $\mu \mathrm{m}$ tissue sections, mounted on glass slides, and then stained by a standard H\&E procedure. All tissue sections were analyzed by a blinded observer without knowledge of the treatment category of the animal and graded for inflammation caused by SGVHD using a previously published grading scale (colon: \pm , rare crypt cell necrosis; $1^{+}$, definite scattered single-cell necrosis in crypts; $2^{+}$, several necrotic cells in gland, crypt abscesses present; $3^{+}$, confluent destruction of glands) [34]. 


\section{Immunohistochemical Staining}

Colonic tissue was taken at the indicated time points, immediately placed in Tissue-Tek Optimal Cutting Temperature compound (Sakura Finetek, Torrance CA, USA) and frozen in liquid nitrogen. Colons were cut into $10-\mu \mathrm{m}$ tissue sections, mounted on glass slides and stored at $-20^{\circ} \mathrm{C}$. Tissues were fixed in 3\% paraformaldehyde for $15 \mathrm{~min}$, washed three times in PBS for 5 min each, then treated with blocking solution containing $2 \mathrm{mg} / \mathrm{ml}$ normal donkey serum (Jackson ImmunoResearch, West Grove, PA), $0.3 \%$ Triton X-100 in PBS for $30 \mathrm{~min}$ to block non-specific binding. All incubations were carried out in a humidified chamber at $4^{\circ} \mathrm{C}$ in the dark. After draining the excess blocking solution the tissues were stained overnight with anti-nitrotyrosine $\mathrm{Ab}$ (1: 50, Upstate, Lake Placid, NY, USA). The Ab-treated slides were washed twice with PBS for $30 \mathrm{~min}$, incubated with Oregon Green 488- conjugated anti-IgG (1 : 1000 dilution, Invitrogen, USA) in PBS containing $2 \mathrm{mg} / \mathrm{ml}$ normal donkey serum and $0.3 \%$ Triton $\mathrm{X}-100$ for $1 \mathrm{~h}$, and then washed twice for 30 min each. Control staining was performed by omitting the primary antibody during the procedure to control for the specificity of the staining of the primary antibody. Samples were visualized with a $100 \mathrm{X}$ objective and digitized with an AxioCam HR Vision System (Carl Zeiss MicroImaging Inc., Thornwood, NY).

\section{Real Time Polymerase Chain Reaction}

Total colon RNA was isolated using Trizol reagent (Invitrogen, Grand Island, NY). $1 \mu \mathrm{g}$ of RNA from each group was reversed transcribed into cDNA using the Promega reverse transcription system (Madison, WI). 2.5 $\mu 1$ of cDNA was combined with $10 \mu \mathrm{l}$ of master mix $(0.5 \mathrm{U}$ Platinum Taq (Invitrogen), $0.2 \mathrm{nM}$ of each dNTP, $0.2 \mathrm{mM}$ PCR buffer (Idaho technology Inc, Salt Lake City, UT), 1X SYBR Green (Molecular probes, Eugene, OR) and $1 \mu \mathrm{M}$ of primer. Primers for GAPDH, TNF- $\alpha$, [35] and iNOS (NOS2)[36] were purchased from Integrated DNA technologies (Coralville, IA). Real time PCR was performed on a Roche Lightcycler (Roche Diagnostics, Indianapolis, IN). PCR conditions were as follows: 5 minutes at $95^{\circ} \mathrm{C}$, followed by 50 cycles of 30 seconds at $95^{\circ} \mathrm{C}, 30$ seconds at $60^{\circ} \mathrm{C}$ for all primers. The amount of TNF- $\alpha$ and iNOS was normalized to GAPDH calculated by the comparative $\mathrm{C}_{\mathrm{T}}$ method.

\section{Statistical Analysis}

Statistical differences between control BMT and SGVHD samples were determined using Student's $t$ test or one-way ANOVA. Induction of SGVHD was monitored by KaplanMeier method and log rank test or Fisher's exact test (induction). Differences $\mathrm{p}<0.05$ were considered statistically different.

\section{RESULTS}

\section{Determination of Oxidative Stress During the Induction of SGVHD}

Oxidative stress is defined as an imbalance between oxidants and antioxidants that can lead to tissue damage and can contribute to the pathology of many different diseases [37]. Since both of the conditioning agents required for the induc- tion of SGVHD can result in the generation of oxidative stress, studies were undertaken to determine the levels of ROS at the completion of CsA therapy. Intracellular ROS production during SGVHD was determined using the fluorescent probe DCFH-DA[33]. Oxidation of DCFH-DA to fluorescent DCF was significantly increased in spleen cells isolated from CsA treated animals by day 21 post-BMT (Fig. 1) when compared to BMT control mice, demonstrating higher levels of ROS in CsA-treated animals.

Since it was demonstrated that NO (post-CsA) played a role in the development of SGVHD [18], real time RT-PCR studies were performed to determine if increases in mRNA for iNOS could be detected in the colon, during the CsA treatment period (d0-21). Increased mRNA for iNOS was present in the colon of CsA treated animals as early as day 14 and at day 21 post-BMT (Fig. 2). As previously published

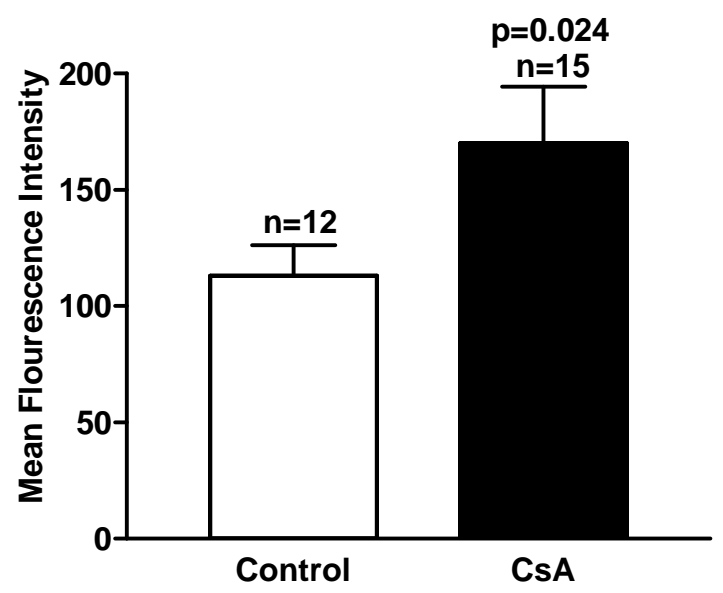

Fig. (1). Elevated ROS in mice treated with CsA compared to control BMT. Spleens were removed from control and CsA-treated mice at day 21 post-BMT. Splenocytes were isolated and treated with DCFH-DA, as described, and analyzed by flow cytometry. Data presented are pooled from four individual experiments, $n$ represents the number of animals per group. Statistical difference determined by unpaired Student's t test.

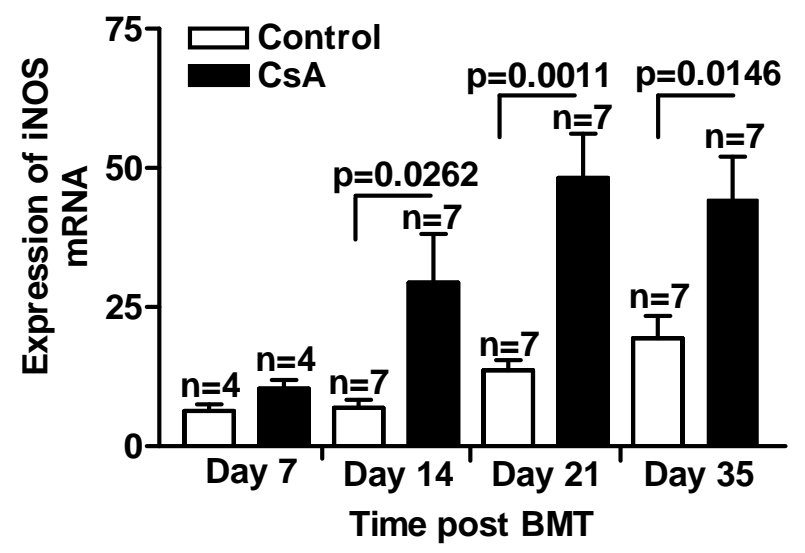

Fig. (2). Increased levels of iNOS mRNA in CsA-treated mice. Animals were induced to develop SGVHD as described. Colon was isolated at 7,14 and 21 days after BMT and analyzed by real time RT-PCR. Data presented represents mean \pm SEM of pooled data from two experiments with $n$ representing the number of mice analyzed within each treatment group. Statistical difference determined by unpaired Student's t test. 
by our group [18], iNOS mRNA levels remain significantly elevated during active disease in colonic tissue of CsA treated mice compared to BMT control. Furthermore, increased circulating NO was observed after nitrate reduction in the pooled serum of SGVHD mice relative to normal or transplant control animals (data not shown), confirming the PCR data. As an additional measure of oxidative stress in the tissues of CsA-treated/SGVHD animals, we monitored protein tyrosine nitration since it is an important marker of oxidative stress induced by peroxynitrite and other nitric-oxide derived oxidants [21, 38]. Increased nitrotyrosine was observed in colonic tissue of CsA treated mice compared to control mice by day 21 post-BMT demonstrating increased oxidation mediated by peroxynitrite (Fig. 3). Taken together, these results demonstrate that CsA-treated mice produced significantly elevated amounts of RNS compared to control BMT mice and confirm that increased oxidative stress is generated in mice undergoing CsA therapy.

\section{Reduction of Oxidative Stress During CsA Therapy Alters the Development of SGVHD}

To determine the role of conditioning/CsA-induced oxidative stress on the development of SGVHD, the antioxidant

A
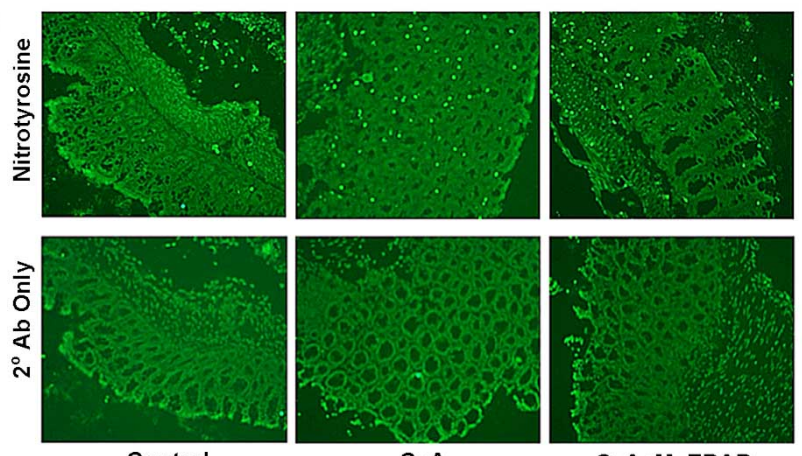

Control

CsA

CsA+MnTBAP

B

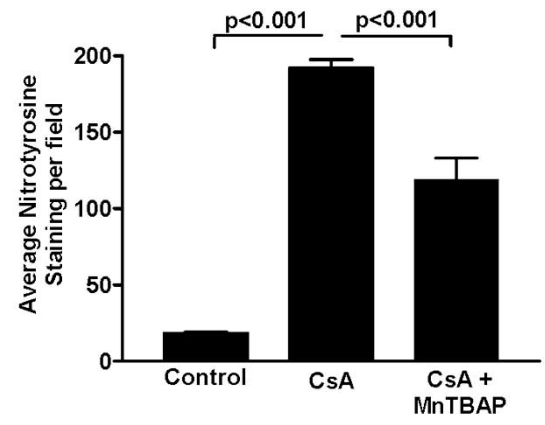

Fig. (3). Reduced nitrotyrosine staining after antioxidant therapy. (A) Colons of $\mathrm{C} 3 \mathrm{H} / \mathrm{HeN}$ mice were removed at day 21 post-BMT and frozen sections were analyzed by immunohistochemistry techniques for the presence of nitrotyrosine (100X). The data presented are representative of samples from four mice from two individual experiments. (B) Slides were visualized under 100X magnification and staining per field was quantified by visually counting the areas that were positive for nitrotyrosine staining. Data presented mean \pm SEM from pooled samples from two experiments. Statistical difference determined by one-way ANOVA.
A

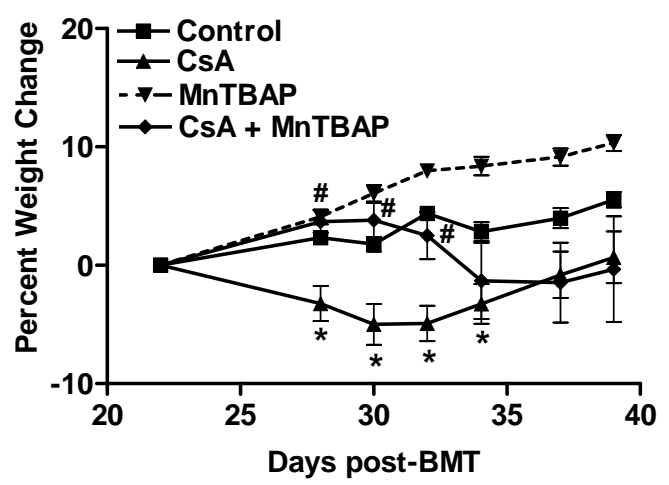

B

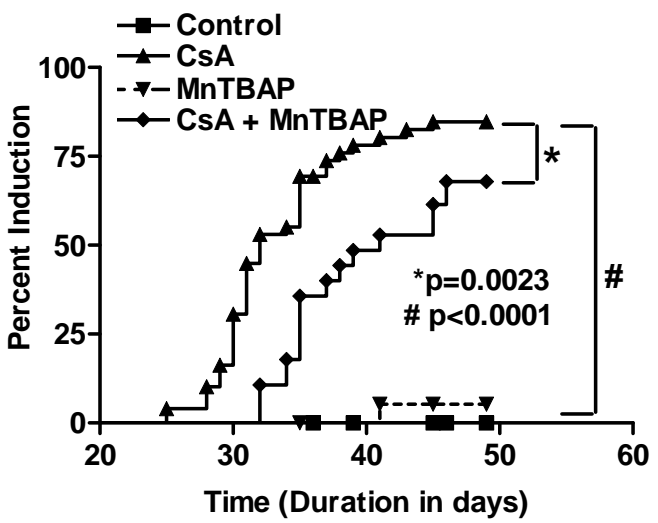

C

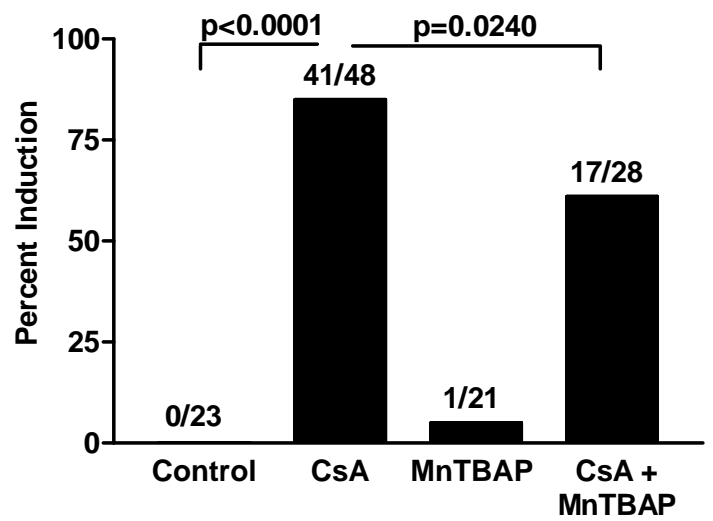

Fig. (4). MnTBAP treatment delayed the development of SGVHD. Disease was induced in $\mathrm{C} 3 \mathrm{H} / \mathrm{HeN}$ mice, as described. Groups of control or CsA-treated mice were given $10 \mathrm{mg} / \mathrm{kg}$ of MnTBAP twice a day starting 2 days prior to BMT and every day for 21 days. The animals were then monitored for SGVHD induction (weight loss, diarrhea and/or mortality). (A) Animals were weighed individually $3 \mathrm{x}$ per week starting on day 21 post-BMT. Data presented represent pooled data from 2 experiments, plotted as average \pm SEM of percent weight change for each treatment group $(n=16)$. Statistical difference determined by unpaired Student's t test. (B) Animals were followed for induction and plotted as time to induction after BMT. Data presented represent pooled data from 4 experiments $(n=16)$. Statistical difference determined by log rank test. (C) Analysis for induction measured 49 days post-BMT, with the number of animals with SGVHD/total number of animals within each group presented above each bar. Data presented are pooled from four experiments. Statistical difference for induction determined by Fisher's exact test. 
MnTBAP, a stable metalloporphyrin that can scavenge a broad spectrum of reactive oxygen and nitrogen species [2630 ], was given during the CsA treatment period. $\mathrm{C} 3 \mathrm{H} / \mathrm{HeN}$ mice were induced for SGVHD as described. Beginning two days prior to BMT, the mice were treated with MnTBAP, 10 $\mathrm{mg} / \mathrm{kg}$ twice a day until day 21 post-BMT [32]. Antioxidant therapy during CsA treatment delayed the weight loss observed in the CsA treated mice (Fig. 4A), as well as delayed development of clinical symptoms of SGVHD (Fig. 4B) and significantly reduced total disease induction through 49 days after cessation of CsA therapy (Fig. 4C). Our results demonstrated that treatment of CsA mice with MnTBAP reduced the severity of SGVHD when compared to mice receiving CsA alone. However, the mechanism by which the SOD mimetic exerted its beneficial actions remained unknown. Given the role that NO played in the pathogenesis of SGVHD, the levels of nitrotyrosine in colonic tissue of CsA treated mice were evaluated and shown to be elevated when compared to transplant controls 21 days after BMT (Fig. 3). However, immunohistochemistry analysis revealed less nitrotyrosine staining in the colons of CsA-treated mice that received MnTBAP compared to mice treated with CsA alone (Fig.3A). In addition, quantitative measurement of nitrotyrosine staining in colonic tissue revealed that MnTBAP treatment was capable of reducing oxidative stress in a significant manner when compared to mice that were only treated with CsA (Fig.3B). Similarly, while not statistically significant, MnTBAP therapy consistently reduced the mRNA for iNOS and TNF- $\alpha$ when analyzed at this time as well (data not shown). These studies demonstrated that treatment with the SOD mimetic reduced production of peroxynitrite in the colon of CsA treated mice, reducing a potent RNS mediator that has been shown to be unregulated during intestinal inflammation associated with inflammatory bowel disease [21].

\section{Reduction of Oxidative Stress by Post-CsA Therapy Alters the Development of SGVHD}

Since our results demonstrated that antioxidant therapy during the 21 days of CsA induction therapy was able to delay disease induction, we analyzed the role of oxidative stress post-CsA therapy in the development of SGVHD. For these experiments, treatment with the antioxidant MnTBAP was given to BMT control and CsA mice after cessation of $\mathrm{CsA}$ therapy. $\mathrm{C} 3 \mathrm{H} / \mathrm{HeN}$ mice were induced for SGVHD as described. Beginning on day 21 post-BMT, the mice were treated with MnTBAP $10 \mathrm{mg} / \mathrm{kg}$ twice a day for 2-3 weeks until CsA-treated BMT mice were positive for SGVHD $(\geq 80 \%)$. Treatment of BMT control and CsA-treated mice with MnTBAP post-CsA delayed the development of clinical symptoms of SGVHD (Fig. 5). Antioxidant therapy postCsA treatment reduced weight loss observed in the CsA treated mice (Fig. 5A), clinical symptoms of SGVHD (weight loss, diarrhea)(Fig. 5B) and disease induction was significantly reduced when antioxidant therapy was initiated after cessation of CsA therapy (Fig. 5C). In addition, MnTBAP treatment after CsA treatment was also capable of reducing nitrotyrosine staining in CsA-treated mice (Fig. 6). These results were not unexpected as our group has previously shown that inhibition of iNOS post-CsA therapy decreased SGVHD induction [18]. Similar to data obtained
A

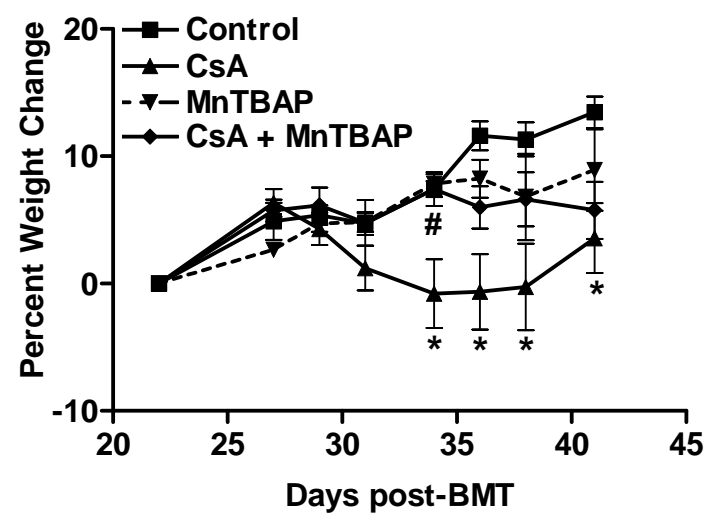

B

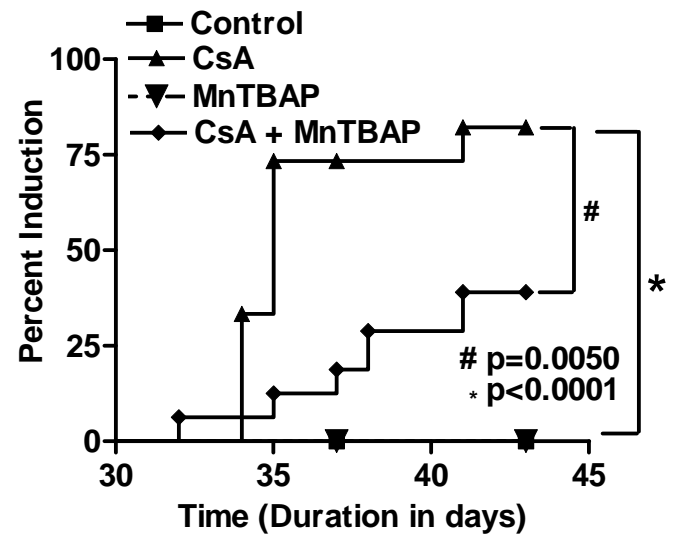

C

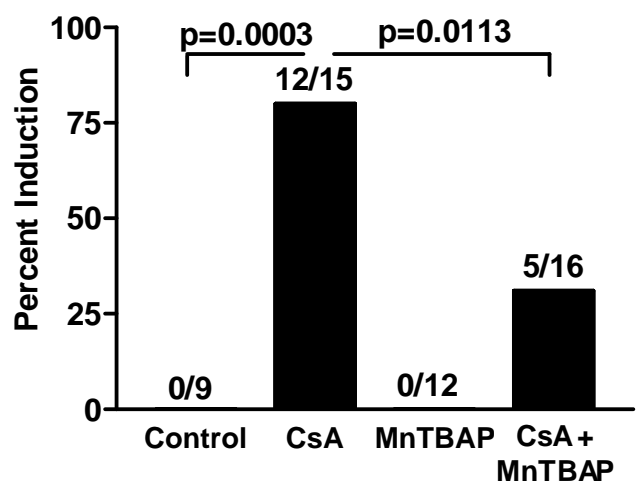

Fig. (5). Delayed SGVHD after MnTBAP treatment post-CsA. Disease was induced in $\mathrm{C} 3 \mathrm{H} / \mathrm{HeN}$ miceas described. Groups of control or CsA-treated mice were treated with $10 \mathrm{mg} / \mathrm{kg}$ of MnTBAP twice a day beginning on day 21 post-BMT through 2-3 weeks post-CsA when the majority $(>80 \%)$ of the CsA animals had developed SGVHD. (A) Animals were weighed individually $3 x$ per week starting on day 21 post-BMT and plotted as mean \pm SEM of percent weight change for each treatment group. Statistical difference determined by unpaired Student's t test. (B) Individual animals were followed for disease induction and plotted as the time to induction after BMT. Statistical difference determined by log rank test. (C) Analysis for disease induction measured 43 days post-BMT, with the number of animals with SGVHD/total number of animals within each group presented above each bar. Data presented are pooled from two experiments. Statistical difference in induction determined by Fisher's exact test. 
A
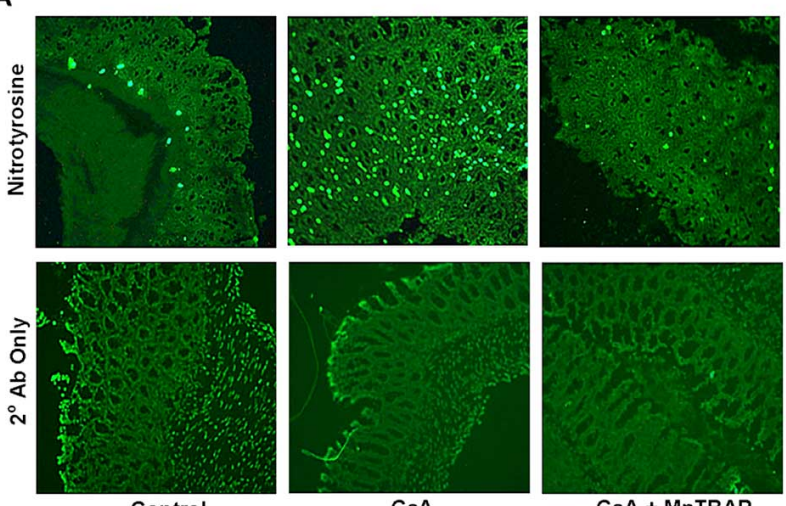

CsA + MnTBAP

B

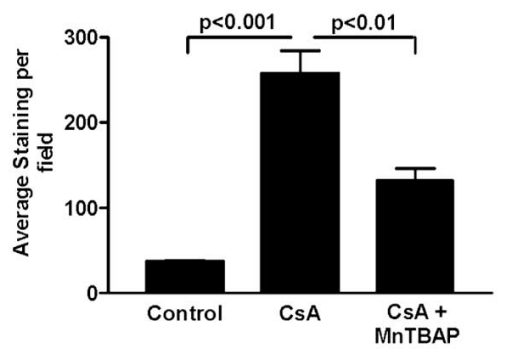

Fig. (6). Decreased RNS in colon of CsA-treated mice after MnTBAP therapy. (A) Colonic tissue was isolated after MnTBAP treatment and analyzed by immunohistochemistry analysis for nitrotyrosine staining in colons of CsA-treated mice compared to control BMT (100X magnification). (B) Nitrotyrosine staining was visually quantified as described. Data are pooled from 2 experiments and represents $n=4$ mice per group. Statistical difference determined by one-way ANOVA.

when MnTBAP was given during CsA therapy, decreased iNOS mRNA levels after antioxidant treatment in the colon of CsA treated mice if compared to mice that received CsA alone (data not shown). Interestingly, while the reduction in the deposition of nitrotyrosine in the colon of MnTBAPtreated animals reduced the development of clinical symptoms of SGVHD, histological analysis of colonic tissue revealed that MnTBAP treatment after CsA therapy did not ameliorate the inflammatory infiltrate observed in CsAtreated mice (Fig. 7).

\section{DISCUSSION}

Previous work in this model has shown a significant role for oxidative stress mediators during the development of SGVHD [18]. Studies presented here demonstrated increased oxidative stress during the induction (d0-21 post-BMT) of SGVHD and the deposition of nitrotyrosine was enhanced in the colons of CsA-treated/SGVHD animals. Based on this finding, the SOD mimetic MnTBAP was utilized during and after SGVHD induction to determine the effects of reduced oxidant stress on disease development. Treatment with MnTBAP during and after induction therapy significantly reduced the development of clinical symptoms of SGVHD and reduced the nitrosylation of target tissues demonstrating

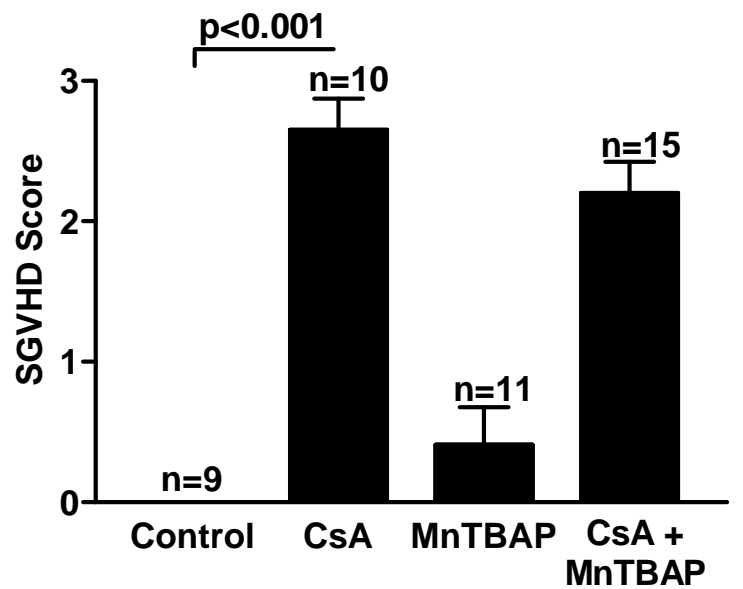

Fig. (7). Colon pathology was not altered by MnTBAP treatment. Colon tissue was isolated during clinical symptoms of SGVHD, typically 3-4 weeks post-CsA treatment. The tissues were stained for $\mathrm{H} \& \mathrm{E}$ and pathology grading was performed as described in Materials and Methods. Data represent mean pathology grade \pm SEM. $n$ represents the number of mice per experimental group pooled from two independent experiments. Statistical difference determined by one-way ANOVA.

a role for reactive oxygen/nitrogen intermediates in the development of this inducible disease.

Utilizing the iNOS inhibitor aminoguanidine (AG), Flanagan et al. demonstrated that AG therapy for 2 weeks after CsA therapy significantly reduced the development of SGVHD. In their studies, iNOS inhibition resulted in the abrogation of clinical symptoms, tissue pathology and cytokine (IL-12 and IFN- $\gamma$ ) levels associated with the development of SGVHD [18]. In accordance, Garside et al. [22] showed that inhibition of iNOS with L-NG-monomethyl arginine (L-NMMA) in their experimental model of mouse GVHD, resulted in decreased intestinal pathology. Alternative to these studies, it was shown that inhibition of NO production at early stages following allogeneic BMT can lead to mortality $[24,25]$, suggesting that NO levels could affect alloengraftment [24] or have a protective effect during this period [25]. For this reason we decided to treat mice with the antioxidant MnTBAP since it can scavenge a broad spectrum of reactive oxygen as well as nitrogen species [28, 29, 32, 39].

In the immediate post-BMT period, radiation conditioning and CsA therapy resulted in elevated production of inflammatory mediators. It was shown that mice treated with CsA had increased levels of oxidative stress as shown by increased fluorescence of the ROS probe, DCFH-DA. Reactive nitrogen species were also elevated in the CsA treated animals compared to their control counterparts. Along with increases in oxidative stress, our group has shown increased levels of TNF- $\alpha$ and cellular adhesion molecules (CAM) in the colons of CsA treated mice compared to control BMT at early time points during and after CsA therapy [40]. The SGVHD induction regimen can trigger oxidative stress in many cell types and reports show that pathological changes associated with TNF- $\alpha$ signaling is associated with increased oxidative stress [41, 42]. 
The potential and beneficial effects of SOD mimetics have highlighted the importance of antioxidant compounds as potential therapeutic treatment for many pathologies [26$28,32,39]$. Simmonds et al. previously demonstrated a direct correlation between increased production of ROS and increased pathogenesis in colorectal biopsy specimens of patients with IBD [43]. Similarly, Rachmilewitz et al. reported increased concentrations of RNS (i.e. NO) in ulcerative colitis and Crohn's disease patients [44]. Thus, evidence exists for increased oxidative stress intermediates in IBD which could participate in the cellular damage observed in intestinal inflammation. Such findings point to the potential of antioxidant therapy as a possible curative option to ameliorate the deleterious effects caused by oxidative stress. Several studies have concentrated on the use of antioxidant therapy as an option to treat colitis with positive outcomes $[45,46]$.The use of antioxidant to promote graft acceptance in animal models has also been successful, supporting the role of ROS/RNS in rejection [47]. In addition, antioxidant therapy in a murine model of GVHD [48] as well as in a clinical allogeneic hematopoietic stem cell transplant trial [49] have been shown to reduce GVHD and improve transplant outcome. These studies lead us to the hypothesis that antioxidant therapy could ameliorate the inflammatory response observed in the colons of SGVHD animals.

Therapy of CsA-treated mice with MnTBAP either during, or after CsA treatment, resulted in a reduction of clinical symptoms and overall disease induction. MnTBAP therapy of CsA-treated mice was shown to be capable of reducing RNS (i.e. $\mathrm{ONOO}^{-}$) with a decreased staining for nitrotyrosine in the colons of CsA-treated/SGVHD animals compared to their control counterparts; peroxynitrite has been shown to change cell membrane rigidity and permeability as well as to induce cell death in renal epithelial cells [50]. A reduction in peroxynitrite could explain why MnTBAP treatment delayed the clinical symptoms of SGVHD by reducing peroxynitrite induced damage to epithelial cells, resulting in a reduction of diarrhea and loss weight. However, while clinical symptoms were reduced in SGVHD animals, and while MnTBAP decreased some inflammatory mediators (i.e. iNOS, TNF- $\alpha$ and CAMs (data not shown), treatment of mice with this antioxidant was not sufficient to prevent the histological changes observed in the SGVHD colon. Since the effector cytokines and CAMs were not significantly reduced by MnTBAP, these changes may not have been enough to alter the migration of effector cells into the gut, but may have reduced the negative effects of oxidative stress on the development of clinical symptoms. The pathophysiology caused by ONOOon gut inflammation (i.e. IBD) has been difficult to predict since there are many oxidative mediators present during intestinal inflammation and neutralization of a specific mediator has been difficult. Finally, we have previously demonstrated that the absence of clinical symptoms did not completely correlate with the absence of hisopathology in SGVHD animals [31].

MnTBAP has been sold commercially as an SOD mimetic and there is some recent evidence that it may not be a specific scavenger of superoxide [26, 30]. Experiments using this compound suggested that commercial MnTBAP is unable to dismutate superoxide in vivo and has been reported to likely scavenge peroxynitrite and carbonate radicals [26]. In our attempt to determine the mechanism of action by which MnTBAP delayed the development of SGVHD, we analyzed mRNA levels of antioxidant enzymes including: SOD, catalase, glutathione reductase (GPx) and NADPH reductase. Real time RT-PCR results revealed that MnTBAP treatment had no effect on any of these antioxidant enzymes (data not shown) in the murine model of SGVHD. These results were surprising since other publications have shown that MnTBAP treatment induces upregulation of antioxidant enzymes [51, 52]. However, there is also evidence that the preconditioning requirements (irradiation and CsA) of SGVHD by themselves can downregulate antioxidant enzyme activity [53-55], thus it is possible that the regimens induced oxidative stress via the downregulation of antioxidant defenses which could not be overcome by MnTBAP treatment. In addition, Cooke et al. showed that under oxidative stress, peroxynitrite formation is enhanced resulting in a positive loop that increases iNOS through the activation of NF- $\mathrm{KB}$ [56]. The possibility exists that MnTBAP treatment scavenged peroxynitrite resulting in the reduction of NF- $\mathrm{KB}-$ induced expression of iNOS, or other inflammatory mediators, that we observed in the murine model of SGVHD. This could explain why MnTBAP treatment both during and postCsA period trended to reduced iNOS and TNF- $\alpha$ mRNA levels in colonic tissue of CsA-treated mice. Flanagan et al. demonstrated that SGVHD can be reduced following treatment with the iNOS inhibitor AG during the post-CsA period [18]. In their studies, AG therapy of CsA-treated mice resulted in decreased tissue pathology along with reduced mRNA levels of pro-inflammatory cytokines (i.e. IL-12 and IFN- $\gamma$ ). Surprisingly, in our results, antioxidant therapy of CsA-treated mice with MnTBAP did not have the same effect and differences between these therapies may be related to their mode of action. Aminoguanidine specifically inhibits iNOS [57] by causing covalent modifications of the iNOS protein and the heme residue at the active site resulting in inactivation of iNOS [58]. Meanwhile, MnTBAP has been reported to scavenge a broader spectrum of oxidative stress mediators. Thus, it is possible that while AG treatment was able to effectively inhibit iNOS enzymatic activity and the generation of RNS, while MnTBAP therapy only decreased it partially through negative feedback loops [56] resulting in a reduction in the production of $\mathrm{NO}$ and downstream generation of ONOO-.

\section{CONCLUSION}

The preconditioning regimens in SGVHD, which include irradiation and CsA, are both known to participate in the generation of oxidative stress. The data presented in this manuscript confirm the hypothesis that SGVHD induction results in increased oxidative stress in CsA-treated mice compared to BMT controls. Treatment with a commercially available SOD mimetic, MnTBAP, during, or after CsA treatment, resulted in delayed disease induction and reduced clinical symptoms of SGVHD. However, the reduction of pro-inflammatory mediators and oxidative stress was not sufficient to completely ameliorate disease induction. The use of a specific inhibitor directed towards peroxynitrite may 
be a more powerful tool, which could lead to a better understanding of the role of oxidative stress in SGVHD.

\section{ACKNOWLEDGEMENTS}

This work was supported by National Institutes of Health Grant PO1 CA092372 (J.S.B.).

\section{CONFLICT OF INTEREST}

None declared.

\section{REFERENCES}

[1] Glazier, A.; Tutschka, P.J.; Farmer, E.R.; Santos, G.W. Graftversus-host disease in cyclosporin A-treated rats after syngeneic and autologous bone marrow reconstitution. J. Exp. Med., 1983, $158,1-8$.

[2] Fischer, A.C.; Beschorner, W.E.; Hess, A.D. Requirements for the induction and adoptive transfer of cyclosporine-induced syngeneic graft-versus-host disease. J. Exp. Med., 1989, 169, 1031-1041.

[3] Fischer, A.C.; Laulis, M.K.; Horwitz, L.; Beschorner, W.E.; Hess, A. Host resistance to cyclosporine induced syngeneic graft-versushost disease. Requirement for two distinct lymphocyte subsets. $J$. Immunol., 1989, 143, 827-832.

[4] Kuwabara, M.; Asanuma, T.; Niwa, K.; Inanami, O. Regulation of cell survival and death signals induced by oxidative stress. J. Clin. Biochem. Nutr., 2008, 43, 51-57.

[5] Green, C.J. Experimental transplantation and cyclosporine. Transplantation, 1988, 46 (2 Suppl), 3S-10S.

[6] Kahan, B.D. Cyclosporine. N. Engl. J. Med., 1989, 321, 17251738 .

[7] Ahmed, S.S.; Napoli, K.L.; Strobel, H.W. Oxygen radical formation during cytochrome P450-catalyzed cyclosporine metabolism in rat and human liver microsomes at varying hydrogen ion concentrations. Mol. Cell. Biochem., 1995, 151, 131-140.

[8] Wang, C.; Salahudeen, A.K. Lipid peroxidation accompanies cyclosporine nephrotoxicity: effects of vitamin E. Kidney Int., 1995, 47, 927-934.

[9] Josephine, A.; Amudha, G.; Veena, C.K.; Preetha, S.P.; Varalakshmi, P. Oxidative and nitrosative stress mediated renal cellular damage induced by cyclosporine A: role of sulphated polysaccharides. Biol. Pharm. Bull., 2007, 30, 1254-1259.

[10] Bryson, J.S.; Jennings, C.D.; Caywood, B.E.; Kaplan, A.M. Induction of a syngeneic graft-versus-host disease-like syndrome in DBA/2 mice. Transplantation, 1989, 48, 1042-1047.

[11] Bryson, J.S.; Jennings, C.D.; Caywood, B.E.; Kaplan, A.M. Strain specificity in the induction of syngeneic graft-versus-host disease in mice. Transplantation, 1991, 51, 911-913.

[12] Bryson, J.S.; Jennings, C.D.; Brandon, J.A.; Perez, J.; Caywood, B.E.; Kaplan, A.M. Adoptive transfer of murine syngeneic graftvs.-host disease by CD4+ T cells. J. Leukoc. Biol., 2007, 82, 13931400 .

[13] Bryson, J.S.; Zhang, L.; Goes, S.W.; Jennings, C.D.; Caywood, B.E.; Carlson, S.L.; Kaplan, A.M. CD4+ T cells mediate murine syngeneic graft-versus-host disease-associated colitis. J. Immunol., 2004, 172, 679-687.

[14] Flanagan, D.L.; Gross, R.; Jennings, C.D.; Caywood, B.E.; Goes, S.; Kaplan, A.M.; Bryson, J.S. Induction of syngeneic graft-versushost disease in LPS hyporesponsive $\mathrm{C} 3 \mathrm{H} / \mathrm{HeJ}$ mice. J. Leukoc. Biol., 2001, 70, 873-880.

[15] Flanagan, D.L.; Jennings, C.D.; Bryson, J.S. Th1 cytokines and NK cells participate in the development of murine syngeneic graftversus-host disease. J. Immunol., 1999, 163, 1170-1177.

[16] Brandon, J.A.; Jennings, C.D.; Kaplan, A.M.; Bryson, J.S. Development of a $\mathrm{T}(\mathrm{H}) 17$ immune response during the induction of murine syngeneic graft-versus-host disease. Cytokine, 2010, 52, 265-273

[17] Brandon, J.A.; Perez, J.; Jennings, C.D.; Cohen, D.A.; Sindhava, V.J.; Bondada, S.; Kaplan, A.M.; Bryson, J.S. Association between chronic liver and colon inflammation during the development of murine syngeneic graft-versus-host disease. Am. J. Physiol. Gastrointest. Liver Physiol., 2010, 299, G602-613.
[18] Flanagan, D.M.; Jennings, C.D.; Goes, S.W.; Caywood, B.E.; Gross, R.; Kaplan, A.M.; Bryson, J.S. Nitric oxide participates in the intestinal pathology associated with murine syngeneic graftversus-host disease. J. Leukoc. Biol., 2002, 72, 762-768.

[19] Nathan, C.; Xie, Q.W. Nitric oxide synthases: roles, tolls, and controls. Cell, 1994, 78, 915-8.

[20] Cuzzocrea, S.; Zingarelli, B.; Caputi, A.P. Peroxynitrate-mediated DNA strand breakage activates poly(ADP-ribose) synthetase and causes cellular energy depletion in a nonseptic shock model induced by zymosan in the rat. Shock, 1998, 9, 336-340.

[21] McCafferty, D.M. Peroxynitrite and inflammatory bowel disease. Gut, 2000, 46, 436-439.

[22] Garside, P.; Hutton, A.K.; Severn, A.; Liew, F.Y.; Mowat, A.M. Nitric oxide mediates intestinal pathology in graft-vs.-host disease. Eur. J. Immunol., 1992, 22, 2141-2145.

[23] Hoffman, R.A.; Nussler, N.C.; Gleixner, S.L.; Zhang, G.; Ford, H.R.; Langrehr, J.M.; Demetris, A.J.; Simmons, R.L. Attenuation of lethal graft-versus-host disease by inhibition of nitric oxide synthase. Transplantation, 1997, 63, 94-100.

[24] Drobyski, W.R.; Keever, C.A.; Hanson, G.A.; McAuliffe, T.; Griffith, O.W. Inhibition of nitric oxide production is associated with enhanced weight loss, decreased survival, and impaired alloengraftment in mice undergoing graft-versus-host disease after bone marrow transplantation. Blood, 1994, 84, 2363-2373.

[25] Hongo, D.; Bryson, J.S.; Kaplan, A.M.; Cohen, D.A. Endogenous nitric oxide protects against $\mathrm{T}$ cell-dependent lethality during graftversus-host disease and idiopathic pneumonia syndrome. $J$. Immunol., 2004, 173, 1744-1756.

[26] Batinic-Haberle, I.; Cuzzocrea, S.; Reboucas, J.S.; Ferrer-Sueta, G.; Mazzon, E.; Di Paola, R.; Radi, R.; Spasojevic, I.; Benov, L.; Salvemini, D. Pure MnTBAP selectively scavenges peroxynitrite over superoxide: comparison of pure and commercial MnTBAP samples to MnTE-2-PyP in two models of oxidative stress injury, an SOD-specific Escherichia coli model and carrageenan-induced pleurisy. Free Radic. Biol. Med., 2009, 46, 192-201.

[27] Day, B.J.; Batinic-Haberle, I.; Crapo, J.D. Metalloporphyrins are potent inhibitors of lipid peroxidation. Free Radic. Biol. Med., 1999, 26, 730-736.

[28] Day, B.J.; Fridovich, I.; Crapo, J.D. Manganic porphyrins possess catalase activity and protect endothelial cells against hydrogen peroxide-mediated injury. Arch. Biochem. Biophys., 1997, 347, 256-262.

[29] Day, B.J.; Shawen, S.; Liochev, S.I.; Crapo, J.D. A metalloporphyrin superoxide dismutase mimetic protects against paraquat-induced endothelial cell injury, in vitro. J. Pharmacol. Exp. Ther., 1995, 275, 1227-1232.

[30] Reboucas, J.S.; Spasojevic, I.; Batinic-Haberle, I. Quality of potent Mn porphyrin-based SOD mimics and peroxynitrite scavengers for pre-clinical mechanistic/therapeutic purposes. J. Pharm. Biomed. Anal., 2008, 48, 1046-1049.

[31] Bryson, J.S.; Jennings, C.D.; Caywood, B.E.; Kaplan, A.M. Thy1+ bone marrow cells regulate the induction of murine syngeneic graft-versus-host disease. Transplantation, 1993, 56, 941-945.

[32] Oury, T.D.; Thakker, K.; Menache, M.; Chang, L.Y.; Crapo, J.D.; Day, B.J. Attenuation of bleomycin-induced pulmonary fibrosis by a catalytic antioxidant metalloporphyrin. Am. J. Respir. Cell. Mol. Biol., 2001, 25, 164-169.

[33] Saito, Y.; Nishio, K.; Yoshida, Y.; Niki, E. Cytotoxic effect of formaldehyde with free radicals via increment of cellular reactive oxygen species. Toxicology, 2005, 210, 235-245.

[34] Bryson, J.S.; Jennings, C.D.; Lowery, D. M.; Carlson, S.L.; Pflugh, D.L.; Caywood, B.E.; Kaplan, A.M. Rejection of an MHC class II negative tumor following induction of murine syngeneic graftversus-host disease. Bone Marrow Transplant., 1999, 23, 363-372.

[35] Giulietti, A.; Overbergh, L.; Valckx, D.; Decallonne, B.; Bouillon, R.; Mathieu, C. An overview of real-time quantitative PCR: applications to quantify cytokine gene expression. Methods, 2001, 25, 386-401.

[36] McAllister, R.D.; Singh, Y.; du Bois, W.D.; Potter, M.; Boehm, T.; Meeker, N.D.; Fillmore, P.D.; Anderson, L.M.; Poynter, M.E.; Teuscher, C. Susceptibility to anthrax lethal toxin is controlled by three linked quantitative trait loci. Am. J. Pathol., 2003, 163, 17351741 .

[37] Sies, H. Role of reactive oxygen species in biological processes. Klin. Wochenschr., 1991, 69, 965-968. 
[38] Kroncke, K.D. Nitrosative stress and transcription. Biol. Chem., 2003, 384, 1365-1377.

[39] Szabo, C.; Day, B.J.; Salzman, A.L. Evaluation of the relative contribution of nitric oxide and peroxynitrite to the suppression of mitochondrial respiration in immunostimulated macrophages using a manganese mesoporphyrin superoxide dismutase mimetic and peroxynitrite scavenger. FEBS Lett., 1996, 381, 82-86.

[40] Perez, J.; Brandon, J.A.; Cohen, D.A.; Jennings, C.D.; Kaplan, A.M.; Bryson, J.S. Accumulation of CD4+ T cells in the colon of CsA-treated mice following myeloablative conditioning and bone marrow transplantation. Am. J. Physiol. Gastrointest. Liver Physiol., 2011, 300, G843-852.

[41] Natarajan, M.; Gibbons, C.F.; Mohan, S.; Moore, S.; Kadhim, M.A. Oxidative stress signalling: a potential mediator of tumour necrosis factor alpha-induced genomic instability in primary vascular endothelial cells. Br. J. Radiol., 2007, 80 Spec No 1, S1322.

[42] Suematsu, N.; Tsutsui, H.; Wen, J.; Kang, D.; Ikeuchi, M.; Ide, T.; Hayashidani, S.; Shiomi, T.; Kubota, T.; Hamasaki, N.; Takeshita, A. Oxidative stress mediates tumor necrosis factor-alpha-induced mitochondrial DNA damage and dysfunction in cardiac myocytes. Circulation, 2003, 107, 1418-1423.

[43] Simmonds, N.J.; Allen, R.E.; Stevens, T.R.; Van Someren, R.N.; Blake, D.R.; Rampton, D.S. Chemiluminescence assay of mucosal reactive oxygen metabolites in inflammatory bowel disease. Gastroenterology, 1992, 103, 186-196.

[44] Rachmilewitz, D.; Stamler, J.S.; Bachwich, D.; Karmeli, F.; Ackerman, Z.; Podolsky, D.K. Enhanced colonic nitric oxide generation and nitric oxide synthase activity in ulcerative colitis and Crohn's disease. Gut, 1995, 36, 718-723.

[45] Kruidenier, L.; Verspaget, H.W. Review article: oxidative stress as a pathogenic factor in inflammatory bowel disease-radicals or ridiculous? Aliment. Pharmacol. Ther., 2002, 16, 1997-2015.

[46] Ishihara, T.; Tanaka, K.; Tasaka, Y.; Namba, T.; Suzuki, J.; Okamoto, S.; Hibi, T.; Takenaga, M.; Igarashi, R.; Sato, K.; Mizushima, Y.; Mizushima, T. Therapeutic effect of lecithinized superoxide dismutase against colitis. J. Pharmacol. Exp. Ther., 2009, 328, 152-164.

[47] Roza, A.M.; Cooper, M.; Pieper, G.; Hilton, G.; Dembny, K.; Lai, C. S.; Lindholm, P.; Komorowski, R.; Felix, C.; Johnson, C.; Adams, M. NOX 100, a nitric oxide scavenger, enhances cardiac allograft survival and promotes long-term graft acceptance. Transplantation, 2000, 69, 227-231.
[48] Amer, J.; Weiss, L.; Reich, S.; Shapira, M.Y.; Slavin, S.; Fibach, E. The oxidative status of blood cells in a murine model of graftversus-host disease. Ann. Hematol., 2007, 86, 753-758.

[49] Colombo, A.A.; Alessandrino, E.P.; Bernasconi, P.; Arcese, G.W.; Rabusin, M.; Bacigalupo, A.; Bernasconi, C. N-acetylcysteine in the treatment of steroid-resistant acute graft-versus-host-disease: preliminary results. Gruppo Italiano Trapianto di Midollo Osseo (GITMO). Transplantation, 1999, 68, 1414-1416.

[50] Piao, X.L.; Cho, E.J.; Jang, M.H.; Cui, J. Cytoprotective effect of lignans from Forsythia suspensa against peroxynitrite-induced LLC-PK1 cell damage. Phytother. Res., 2009, 23, 938-942.

[51] Ferret, P.J.; Hammoud, R.; Tulliez, M.; Tran, A.; Trebeden, H.; Jaffray, P.; Malassagne, B.; Calmus, Y.; Weill, B.; Batteux, F. Detoxification of reactive oxygen species by a nonpeptidyl mimic of superoxide dismutase cures acetaminophen-induced acute liver failure in the mouse. Hepatology, 2001, 33, 1173-1180.

[52] Malassagne, B.; Ferret, P.J.; Hammoud, R.; Tulliez, M.; Bedda, S.; Trebeden, H.; Jaffray, P.; Calmus, Y.; Weill, B.; Batteux, F. The superoxide dismutase mimetic MnTBAP prevents Fas-induced acute liver failure in the mouse. Gastroenterology, 2001, 121, 1451-1459.

[53] Prasad, N.R.; Menon, V.P.; Vasudev, V.; Pugalendi, K.V. Radioprotective effect of sesamol on gamma-radiation induced DNA damage, lipid peroxidation and antioxidants levels in cultured human lymphocytes. Toxicology, 2005, 209, 225-235.

[54] Kumar, K.B.; Kuttan, R. Protective effect of an extract of Phyllanthus amarus against radiation-induced damage in mice. $J$. Radiat. Res. (Tokyo), 2004, 45, 133-139.

[55] Pari, L.; Sivasankari, R. Effect of ellagic acid on cyclosporine Ainduced oxidative damage in the liver of rats. Fundam. Clin. Pharmacol., 2008, 22, 395-401.

[56] Cooke, C.L.; Davidge, S.T. Peroxynitrite increases iNOS through NF-kappaB and decreases prostacyclin synthase in endothelial cells. Am. J. Physiol. Cell. Physiol., 2002, 282, C395-402.

[57] Hoffman, R.; Nussler, N.; Gleixner, S.; Zhang, G.; Ford, H.; Langrehr, J.; Demetris, A.; Simmons, R. Attenuation of lethal graft-versus-host disease by inhibition of nitric oxide synthase. Transplantation, 1997, 63, 94-100.

[58] Bryk, R.; Wolff, D.J. Mechanism of inducible nitric oxide synthase inactivation by aminoguanidine and L-N6-(1-iminoethyl)lysine. Biochemistry, 1998, 37, 4844-4852.

(C) Perez et al.; Licensee Bentham Open.

This is an open access article distributed under the terms of the Creative Commons Attribution License (http://creativecommons.org/licenses/by/2.5/), which permits unrestrictive use, distribution, and reproduction in any medium, provided the original work is properly cited. 